\title{
Sex-Based Variations in the Clinical Manifestations, Comorbidities, and Outcomes of Patients With COVID-19 in Baghdad, Iraq, 2020
}

Nameer A Ali ${ }^{1}$; Faris Lami $^{2}$

${ }^{1}$ Ministry of Health, Baghdad, Iraq

${ }^{2}$ University of Baghdad, College of Medicine, Baghdad, Iraq

\section{Corresponding Author:}

Nameer A Ali

Ministry of Health

6 Alghazaliya

Baghdad

Iraq

Phone: 9647812111974

Email: nameeraali74@gmail.com

\begin{abstract}
Background: A higher incidence of COVID-19 in males has been widely reported. However, whether clinical manifestations, comorbidities, severity, and outcomes differ between males and females remains an area of active investigation.

Objective: We aimed to compare the clinical features, comorbidities, severity, and outcomes between male and female patients with COVID-19 from Baghdad, Iraq, in 2020.

Methods: We performed a records-based cross-sectional study by extracting sociodemographic, clinical manifestation, severity, and outcome data from the records of patients with COVID-19 admitted to 2 COVID-19 hospitals in Baghdad, Iraq, between June and August 2020.

Results: We reviewed a total of 2111 patient records with a history of COVID-19, and $1175(55.7 \%)$ patients were males. We found that respiratory symptoms, sore throat, and gastrointestinal manifestations were significantly more common among females. In contrast, males had significantly more "other" manifestations. No significant difference was noted for fever, nasal congestion, conjunctival congestion, headache, and musculoskeletal manifestations. Generally, female patients had a significantly higher proportion of comorbidities than males $(42.7 \%$ vs $36 \% ; P=.002)$. The proportion of severe and critical cases was not different between males and females. The mean time from diagnosis to the outcome was significantly longer in females $(P=.03)$, but the duration of the hospital stay was not significantly different between males and females. Finally, the case fatality ratio was higher in males $(16.1 \%)$ than in females $(13.2 \%)$.
\end{abstract}

Conclusions: Sex affects the clinical course and outcomes of patients with COVID-19. Male patients may need more attention, considering the higher case fatality ratio.

(iproc 2022;8(1):e36470) doi: $10.2196 / 36470$

\section{KEYWORDS}

COVID-19; Iraq; sex; case fatality ratio; comorbidity

Edited by Y Khader; this is a non-peer-reviewed article. Submitted 15.01.22; accepted 17.01.22; published 04.02.22.
Please cite as:
Ali NA, Lami F
Sex-Based Variations in the Clinical Manifestations, Comorbidities, and Outcomes of Patients With COVID-19 in Baghdad, Iraq,
2020
iproc $2022 ; 8(1):$ :e36470
URL: $\underline{\text { https://www.iproc.org/2022/1/e36470 }}$
doi: $10.2196 / 36470$
PMID:


(CNameer A Ali, Faris Lami. Originally published in Iproceedings (https://www.iproc.org), 04.02.2022. This is an open-access article distributed under the terms of the Creative Commons Attribution License (https://creativecommons.org/licenses/by/4.0/), which permits unrestricted use, distribution, and reproduction in any medium, provided the original work, first published in Iproceedings, is properly cited. The complete bibliographic information, a link to the original publication on https://www.iproc.org/, as well as this copyright and license information must be included. 